\title{
The epigenetic modifier trichostatin A, a histone deacetylase inhibitor, suppresses proliferation and epithelial-mesenchymal transition of lens epithelial cells
}

\author{
X Chen ${ }^{1,2}$, W Xiao ${ }^{1,2}$, W Chen ${ }^{1}$, L Luo ${ }^{1}, S$ Ye ${ }^{1}$ and Y Liu ${ }^{\star, 1}$
}

Proliferation and epithelial-mesenchymal transition (EMT) of lens epithelium cells (LECs) may contribute to anterior subcapsular cataract (ASC) and posterior capsule opacification (PCO), which are important causes of visual impairment. Histone deacetylases (HDACs)-mediated epigenetic mechanism has a central role in controlling cell cycle regulation, cell proliferation and differentiation in a variety of cells and the pathogenesis of some diseases. However, whether HDACs are involved in the regulation of proliferation and EMT in LECs remain unknown. In this study, we evaluated the expression profile of HDAC family (18 genes) and found that class I and II HDACs were upregulated in transforming growth factor $\beta 2$ (TGF $\beta 2$ )-induced EMT in human LEC lines SRA01/04 and HLEB3. Tricostatin A (TSA), a class I and II HDAC inhibitor, suppressed the proliferation of LECs by G1 phase cell cycle arrest not only through inhibition of cyclin/CDK complexes and induction of p21 and p27, but also inactivation of the phosphatidylinositol-3-kinase/Akt, p38MAPK and ERK1/2 pathways. Meanwhile, TSA strongly prevented TGF $\beta 2$-induced upregulation of fibronectin, collagen type I, collagen type IV, N-cadherin, Snail and Slug. We also demonstrated that the underlying mechanism of TSA affects EMT in LECs through inhibiting the canonical TGF $\beta / S m a d 2$ and the Jagged/Notch signaling pathways. Finally, we found that TSA completely prevented TGF $\beta 2$-induced ASC in the whole lens culture semi-in vivo model. Therefore, this study may provide a new insight into the pathogenesis of ASC and PCO, and suggests that epigenetic treatment with HDAC inhibitors may be a novel therapeutic approach for the prevention and treatment of ASC, PCO and other fibrotic diseases.

Cell Death and Disease (2013) 4, e884; doi:10.1038/cddis.2013.416; published online 24 October 2013

Subject Category: Experimental Medicine

Cataract is the most common cause of visual impairment in the elderly all over the world. ${ }^{1}$ Anterior subcapsular cataract (ASC) and posterior capsule opacification (PCO) are two types of cataract but share many cellular and molecular features., ${ }^{2,3}$ $\mathrm{PCO}$, also known as a secondary cataract, is a major long-term complication of cataract surgery, occurring in $20-40 \%$ of patients after cataract surgery, particularly, in children and infants., ${ }^{4,5}$ In the last few decades, although advances in surgical techniques, intraocular lens materials and designs have reduced the $\mathrm{PCO}$ rate, it is still a significant problem. Currently, there is no generally accepted pharmacologic agent that can prevent or slow down the onset or the progression of these diseases. Cataract surgery and $\mathrm{Nd}$ :YAG laser capsulotomy are the only effective treatments for ASC and PCO, nevertheless, they carry vision-related complications and risks, and put a significant financial burden on the health-care system.
The growing body of evidence shows that proliferation and epithelial-mesenchymal transition (EMT) of lens epithelial cells (LECs) are the major pathologic changes in development of $\mathrm{ASC}^{6,7}$ and $\mathrm{PCO} .^{8,9}$ Transforming growth factor $\beta$ (TGF $\beta$ ), especially TGF $\beta 2$, the major isoform in the aqueous humor of the eye, is the most important factor driving the transdifferentiation and pathologic fibrosis of LECs. ${ }^{10} \mathrm{PCO}$ is caused by a wound-healing response of residual LECs at the equator and under the anterior lens capsule. After surgery, the residual LECs proliferate and undergo EMT, which leads to the formation of fibroblasts and the expression of numerous extracellular matrix proteins, such as collagen type I (Col I), Col IV and fibronectin (FN). ${ }^{11}$ Moreover, LECs undergo cytoskeletal rearrange and loss of epithelial phenotype, then migrate away from the original location onto the posterior capsule, and finally contribute to the development of PCO. ${ }^{7}$

\footnotetext{
${ }^{1}$ State Key Laboratory of Ophthalmology, Zhongshan Ophthalmic Center, Sun Yat-sen University, Guangzhou 510060, People's Republic of China

*Corresponding author: Y Liu, State Key Laboratory of Ophthalmology, Zhongshan Ophthalmic Center, Sun Yat-Sen University, Guangzhou 510060, People's Republic of China. Tel: 86020 87330293; Fax: 86020 87333271; E-mail: yizhi_liu@aliyun.com

${ }^{2}$ These authors contributed equally to this work.

Keywords: histone deacetylase inhibitor; lens epithelium cells (LECs); proliferation; epithelial-mesenchymal transition (EMT); anterior subcapsular cataract (ASC); posterior capsule opacification (PCO)

Abbreviations: ASC, anterior subcapsular cataract; PCO, posterior capsule opacification; EMT, epithelial-mesenchymal transition; LECs, lens epithelial cells; TGF $\beta$, transforming growth factor $\beta$; Col I, collagen type I; Col IV, collagen type IV; HDAC, histone deacetylases; CDK, cyclin-dependent kinase; PI3K, phosphatidylinositol-3kinase; MAPKs, mitogen-activated protein kinases; ERK, extracellular signal-regulated kinase; N1ICD, Notch-1 intracellular domain; FN, fibronectin; TSA, tricostatin A; BSA, bovine serum albumin

Received 30.7.13; revised 10.9.13; accepted 17.9.13; Edited by A Finazzi-Agró
} 
ASC is a primary cataract, which is caused by the proliferation and EMT of LECs in situ. These fibroblasts form subcapsular plaques beneath the lens capsule, and similar to the transdifferentiated cells in $\mathrm{PCO}{ }^{2}$ Based on the above observations, inhibition of LECs proliferation, migration and TGF $\beta$-induced EMT may be a promising strategy to prevent ASC and PCO.

Histone deacetylases (HDACs)-mediated epigenetic mechanism has a central role in controlling cell cycle regulation, cell proliferation and differentiation in a variety of cells and the pathogenesis of some diseases. ${ }^{12,13}$ Multiple studies suggest that HDACs are vital targets in various diseases, including cancers, inflammatory diseases and metabolic disorders. ${ }^{13}$ For this reason, HDAC inhibitors now are potential antitumor drugs. ${ }^{14,15}$ To date, 18 human HDAC isoforms have been characterized and divided into four major classes: class I HDACs (HDAC1, 2, 3 and 8), class II HDACs (HDAC4, 5, 6, 7, 9 and 10), class III HDACs (SIRT1, 2, 3, 4, 5, 6 and 7) and class IV HDAC (HDAC11). ${ }^{16}$ Class II HDACs are further subdivided into class Ila (HDAC4, 5, 7, 9) and class IIb (HDAC6 and 10) forms. ${ }^{16}$ Recently, HDAC inhibitors are also shown to be promising new compounds for the therapy of fibrotic diseases. ${ }^{17,18}$ A class I and II HDAC inhibitor, tricostatin A (TSA), inhibited trans-differentiation of hepatic stellate cells into myofibroblasts, ${ }^{19}$ and also abrogated TGF $\beta 2$-induced EMT in human renal epithelial cells and skin fibroblasts. ${ }^{17,20,21}$ Spiruchostatin A, a class I HDAC inhibitor, suppresses proliferation and differentiation of fibroblasts in human pulmonary fibrosis. ${ }^{22}$ Despite its definite effects on proliferation and EMT inhibition, the underlying mechanisms remain to be clarified. ${ }^{17}$ Moreover, the function of HDAC inhibitor in LECs proliferation and EMT is still unknown.

In current study, we reported, for the first time, that some of class I and class II HDACs were upregulated in TGF $\beta 2$ induced EMT in human LEC lines SRA01/04 and HLEB3. Inhibition of HDAC activity with TSA strongly suppressed proliferation and TGF $\beta 2$-induced EMT of LECs. Moreover, we also demonstrated that TSA completely prevented TGF $\beta 2$-induced ASC in the whole lens culture semi-in vivo model. These results suggest that inhibition of HDAC activity may be of benefit in the treatment of ASC and PCO.

\section{Results}

Expression of HDACs in TGF $\beta 2$-induced EMT of LECs. Aberrant expression of different HDACs has been observed in various tumors and linked to tumor progression and poor outcome. ${ }^{23}$ So we first evaluated the expression pattern of the HDAC family (18 genes) in TGF $\beta 2$-induced EMT in human LEC lines SRA01/04 and HLEB3 by real-time PCR. The result showed that HDAC1, HDAC2, HDAC3, HDAC5, HDAC8 and HDAC10 were upregulated in TGF $\beta 2$-induced SRA01/04 cells, meanwhile, HDAC2, HDAC5 and HDAC10 were upregulated in HLEB3 cells, whereas the expression of other HDAC family members were not significantly changed after $24 \mathrm{~h}$ TGF $\beta 2$ treatment (Figures $1 \mathrm{a}$ and $\mathrm{b}:{ }^{*} P<0.05$ versus the control group). These results suggest that several family members of class I and II HDACs are upregulated in TGF $\beta 2$-induced EMT in LECs.
The HDAC inhibitor TSA suppressed proliferation of LECs by cell cycle arrest. Proliferation of LECs is the fundamental step during ASC and PCO, so we first examined the effect of the HDAC inhibitor TSA on proliferation of LEC lines SRA01/04 and HLEB3. As shown in Figure 2a, TSA $(0.2,0.4$ and $0.8 \mu \mathrm{M})$ exerted strongly inhibitory effects on the proliferation of both SRA01/04 and HLEB3 cells after treatment for $48 \mathrm{~h}(P<0.05)$, but has no effect after $24 \mathrm{~h}$ $(P>0.05)$. To determine if the cell growth inhibition observed was due to apoptosis induced by TSA, the apoptosis of cells were analyzed using flow cytometry. The results showed that TSA at high doses 0.4 and $0.8 \mu \mathrm{M}$ caused an increase in the number of cells death in both SRA01/04 and HLEB3 cells after treatment for $48 \mathrm{~h}$ (Supplementary Figure 1). These results indicate that the inhibitory effect of low dose of TSA $(0.2 \mu \mathrm{M})$ on growth inhibition is mainly due to the suppression of proliferation, whereas the effect of high doses of TSA is partly due to induction of apoptosis. We further examined cell cycle progression to determine whether the anti-proliferative effect of TSA might result from cell cycle arrest. As shown by the results of flow cytometry, SRA01/04 and HLEB3 cells cultured with various concentrations of TSA for $24 \mathrm{~h}$ showed an accumulation of cells in G1 phase of the cell cycle, with concomitant decreases in the proportion of those in G2 and $S$ phases (Figure $2 b$ ). To investigate the underlying mechanism of cell cycle arrest, the effect of TSA on the expression of cell cycle-regulated proteins were examined by western blot analysis. The results revealed that TSA significantly decreased the protein levels of cyclin D1, cyclin E1, cyclin-dependent kinase (CDK) 2, CDK4 and CDK6, whereas increased the expression of P21 and P27 in a concentration-dependent manner in SRA01/04 and HLEB3 cells (Figure $2 \mathrm{c}$ ). These results suggest that TSA inhibits the proliferation of LEC lines SRA01/04 and HLEB3 by G1 phase cell cycle arrest through inhibition of cyclin D1/CDK4/6 and cyclin E1/CDK2 complexes, and induction of P21 and P27.

TSA inhibited LECs proliferation through suppressing the PI3K/Akt, p38MAPK and ERK1/2 signaling pathways. Many reports have demonstrated that the phosphatidylinositol-3-kinase (PI3K)/Akt, mitogen-activated protein kinases (MAPKs), including extracellular signal-regulated kinase (ERK) and p38 pathways have been demonstrated to have key roles in promoting cell proliferation, adhesion, survival and motility. ${ }^{24,25}$ To elucidate the mechanisms responsible for the inhibitory effect of TSA on proliferation of LECs, we examined the phosphorylation of Akt, p38MAPK and ERK1/2 in SRA01/04 and HLEB3 cells. As shown in Figure 3a, TSA decreased the expression of PI3K, as well as the phosphorylation of Akt, p38MAPK and ERK1/2 in a dose-dependent manner without affecting their total protein levels at $60 \mathrm{~min}$ after TSA treatment in both cell lines. These results suggest that TSA potently inhibits the proliferation of LECs by inactivating PI3K/Akt, p38MAPK and ERK1/2 signaling pathways.

TSA prevented TGF $\beta 2$-induced EMT and migration in LECs. To explore whether HDAC inhibition could prevent TGF $\beta 2$-induced EMT in LECs, EMT markers, such as FN, Col I, Col IV, N-cadherin, were investigated at mRNA and 

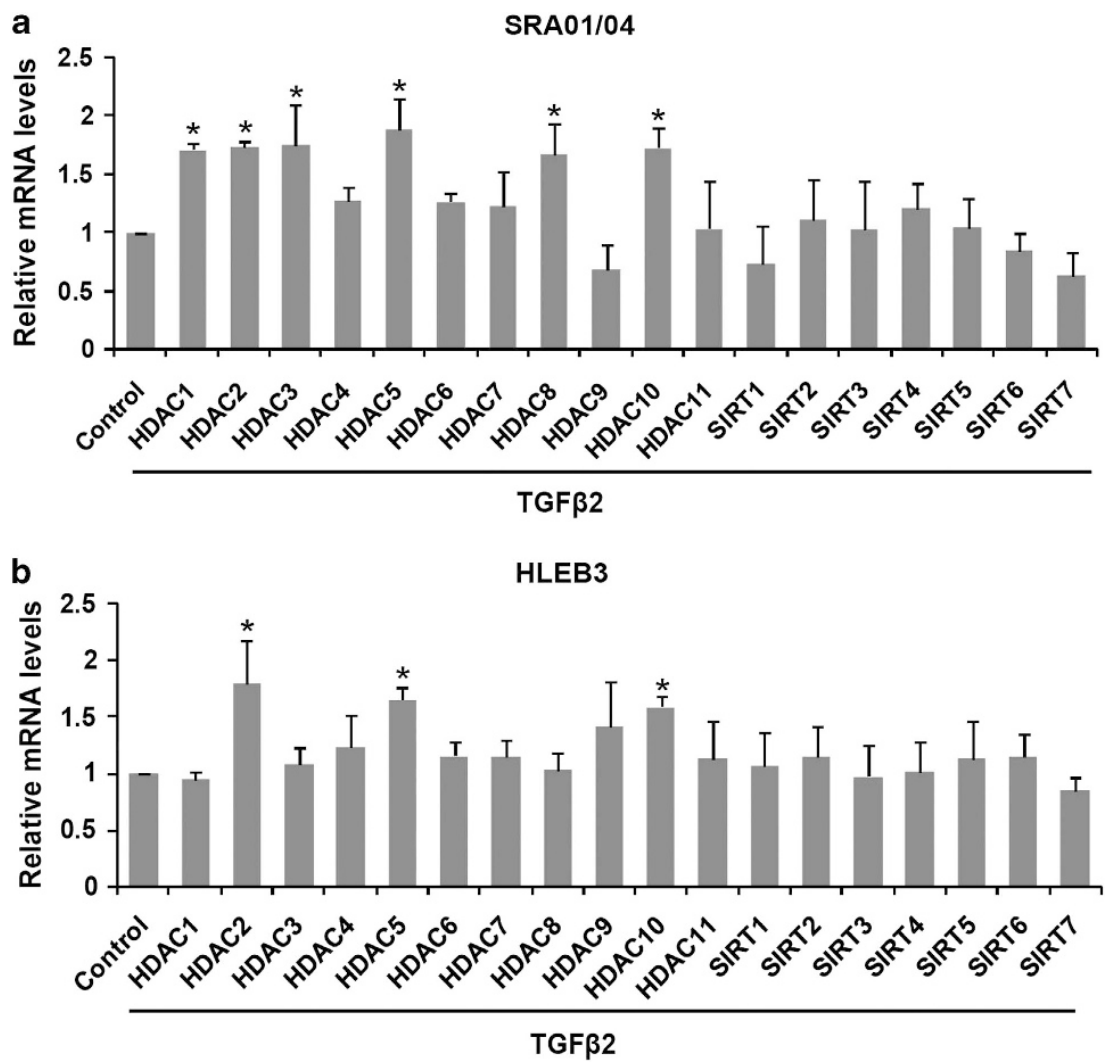

Figure 1 Expression of HDACs in TGF $\beta 2$-induced EMT in LECs. Cells were cultured in the presence or absence of TGF $\beta 2$ ( $10 \mathrm{ng} / \mathrm{ml})$ for $24 \mathrm{~h}$, and the $\mathrm{mRNA}$ expression levels of HDAC family (18 isoforms) were detected by real-time quantitative PCR. (a) Expression of HDACs in TGF $\beta 2$-induced EMT in SRA01/04 cells. (b) Expression of HDACs in TGF $\beta 2$-induced EMT in HLEB3 cells. All experiments were repeated three times with similar results. The expression of each HDAC was normalized separately to its untreated counterpart. ${ }^{*} P<0.05$ versus the control group

protein levels by real-time PCR and western blot analysis, respectively. As shown in Figure 4, TGF $\beta 2$ significantly increased the expression of FN, Col I, Col IV, N-cadherin at both mRNA (Figure 4a) and protein levels in SRA01/04 and HLEB3 cells (Figure 4b). In agreement with these, immunofluorescence staining of $\mathrm{FN}$, Col I and $\mathrm{N}$-cadherin were also enhanced obviously (Figures $5 \mathrm{a}$ and b). On the contrary, TSA completely abrogated the upregulation of FN, Col I, Col IV and N-cadherin, as well as weakened the staining of $\mathrm{FN}$, Col I and N-cadherin in SRA01/04 and HLEB3 cells (Figures $4 \mathrm{a}$ and b: ${ }^{*} P<0.05$ versus TGF $\beta 2$ treated with DMSO group; Figures $5 \mathrm{a}$ and $\mathrm{b})$. Furthermore, the effect of TSA on migration of LECs stimulated by TGF $\beta 2$ was assessed using scratch wound assay. HLEB3 cells treated with TGF $\beta 2$ exhibited an enhanced ability to migrate and the area of wound decreased after injury for $24 \mathrm{~h}$, whereas the wound area remained wide in TGF $\beta 2$ co-treatment with TSA group (Supplementary Figures b and $\mathrm{d},{ }^{*} P<0.05$ versus TGF $\beta 2$ treated with DMSO group). Meanwhile, TGF $\beta 2$ did not induce SRA01/04 cells to migrate, just as the cells cultured without TGF $\beta 2$, however, the wound of the cells treated with TSA was wider than the control and TGF $\beta 2$ treatment groups (Supplementary Figures $2 \mathrm{a}$ and $\mathrm{c},{ }^{*} P<0.05$ versus the control and TGF $\beta 2$ treated with DMSO groups). Taken together, these data indicate that HDAC inhibitor TSA can powerfully attenuate TGF $\beta 2$-induced EMT and migration in LECs.
TSA abrogated TGF $\beta 2$-induced upregulation of Snail and Slug. Snail and Slug are the most widely recognized as important regulators in EMT. In fact, most known EMT events during cancer development and fibrosis appear to be associated with Snail and Slug activation. ${ }^{26}$ Therefore, we next investigated whether the effects of TSA on LECs EMT are mediated through regulating the expression of Snail and Slug. As documented in Figure 6, TGF $\beta 2$ treatment distinctly increased Snail and Slug expression at mRNA and protein levels, nevertheless, TSA dramatically abrogated the upregulation of Snail and Slug induced by TGF $\beta 2$ in SRA01/04 and HLEB3 cells. These results strongly suggest that inhibition of HDACs contributes to downregulation of Snail and Slug, resulting in the prevention of EMT phenotype in LECs.

TSA inhibited TGF $\beta 2$ signaling pathway by suppressing phosphorylation of Smad2. To clarify whether the inhibitory effect of TSA on LECs EMT is partly via blocking the TGF $\beta 2$ signaling pathway, the impact of TSA on activation of receptor-regulated Smad proteins Smad2 and Smad3 were investigated. As shown in Figure 6e, TGF $\beta 2$ alone activated Smad2 and Smad3 via the stimulated phosphorylation after treatment for 60 min, whereas co-treatment with TSA inhibited phosphorylation of Smad2, but did not alter phosphorylation of Smad3 in both SRA01/04 and HLEB3 cell lines. These results suggest that TSA inhibits TGF $\beta 2$ signaling pathway transduction via suppressing phosphorylation of Smad2. 

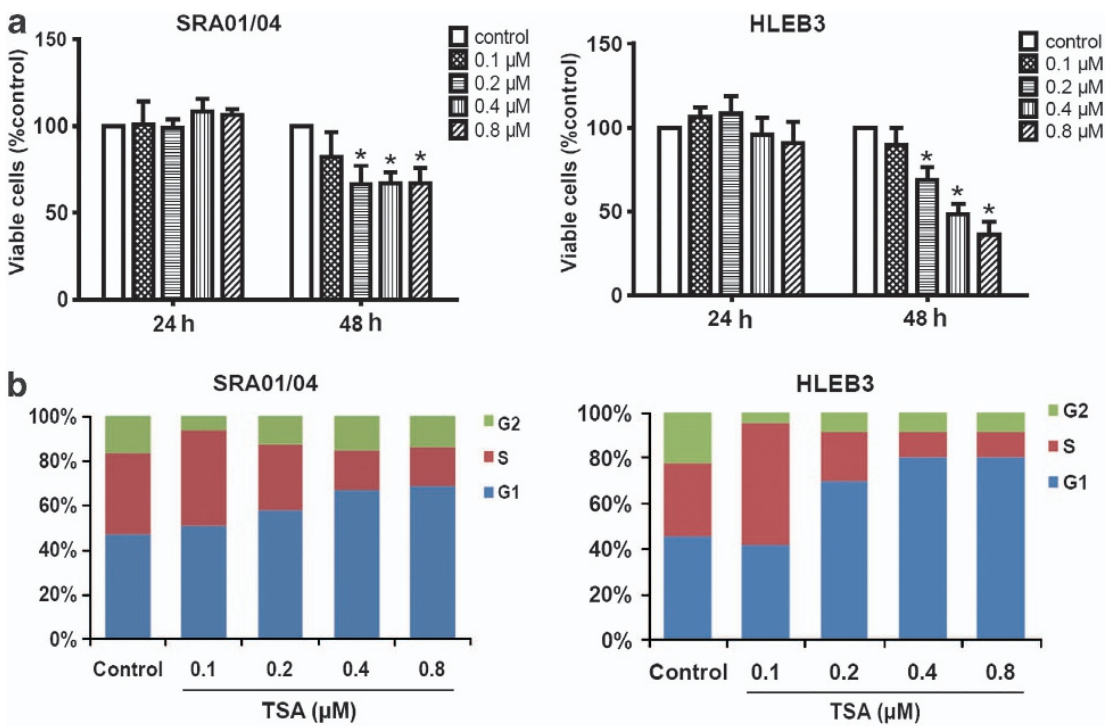

C
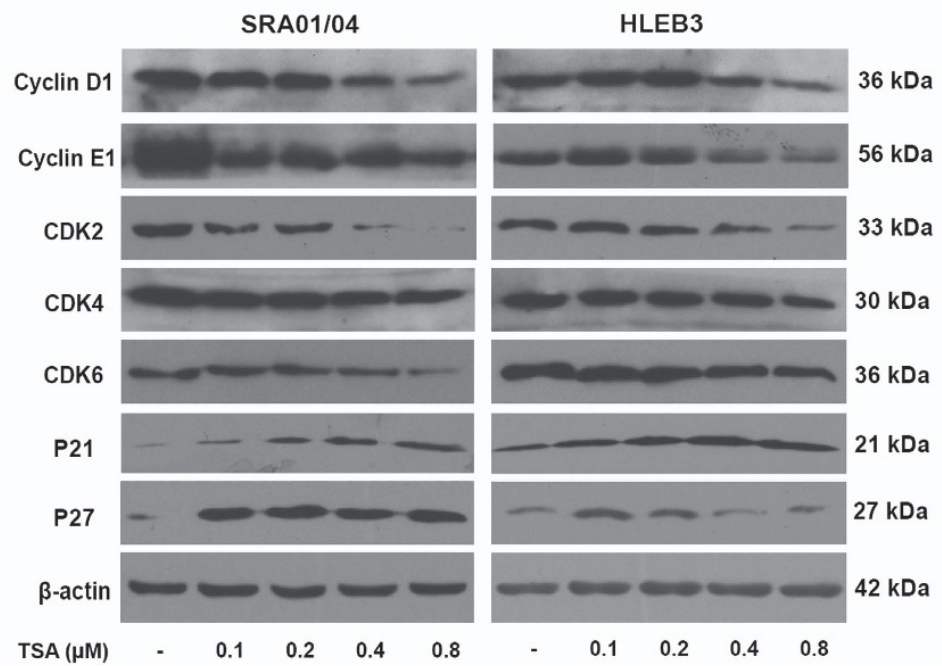

Figure 2 The HDAC inhibitor TSA suppressed proliferation of LECs by cell cycle arrest. (a) SRA01/04 and HLEB3 cell lines were treated with TSA at various concentrations $(0.1,0.2,0.4$, and $0.8 \mu \mathrm{M})$ for 24 and $48 \mathrm{~h}$, then the percentage of viable cells was determined by CCK- 8 kit. ${ }^{*} P<0.05$ versus the control group. (b) Cell cycle analysis of SRA01/04 and HLEB3 cell lines were quantified by PI staining followed by flow cytometry analyses after treatment for $24 \mathrm{~h}$. Bar graphs represent the mean \pm S.E.M. of three independent experiments. (c) The protein expression levels of cyclin D1, cyclin E1, CKD2, CDK4 CDK6, P21 and P27 were detected by western blot analysis after treatment for $24 \mathrm{~h}$ in SRA01/04 and HLEB3 cell lines. All experiments were repeated three times with similar results

TSA increased acetylated histones $\mathrm{H} 3$ and $\mathrm{H} 4$. To investigate whether the observed effects of TSA are due to direct modification of histone acetylation, the levels of acetylated histones $\mathrm{H} 3$ and $\mathrm{H} 4$ were analyzed by western blot analysis. As shown in Figure $3 b$, the amount of acetylated histones H3 (Lys9 and Lys14) and H4 (Lys8) were sharply increased by treatment with TSA in a concentration-dependent manner in SRA01/04 and HLEB3 cells. These results indicate that the effects of TSA on LECs proliferation and EMT are primarily owing to direct modification of histone acetylation.

TSA abrogated TGF $\beta 2$-induced EMT via downregulating the Notch pathway. Emerging evidence suggest that the Notch signaling pathway is a vital regulator in the induction of EMT during embryonic development, fibrotic diseases and cancer metastasis. ${ }^{27}$ Our previous studies also demonstrated that Jagged/Notch pathway is required in TGF $\beta 2$ induced EMT in human LECs and retinal pigment epithelial cell in association with the induction of Notch ligands and receptors, whereas blockade of Notch pathway reverses TGF $\beta 2$-induced EMT (data unpublished). To investigate whether the inhibitory effect of TSA on LECs EMT is partly mediated via regulating the Notch signaling, the impact of TSA on Notch pathway was further accessed. In accordance with our previous research, TGF $\beta 2$ treatment significantly increased the expression of Jagged-1, Notch-1, Notch-2, Notch-1 intracellular domain (N1ICD) as well as their downstream genes Hes-1 and Hey-1 in LECs. In contrast, TSA could completely attenuate the TGF $\beta 2$-induced upregulation of Jagged-1, Notch-1, Notch-2, N1ICD, together with target genes Hes-1 and Hey-1 in both SRA01/04 and HLEB3 

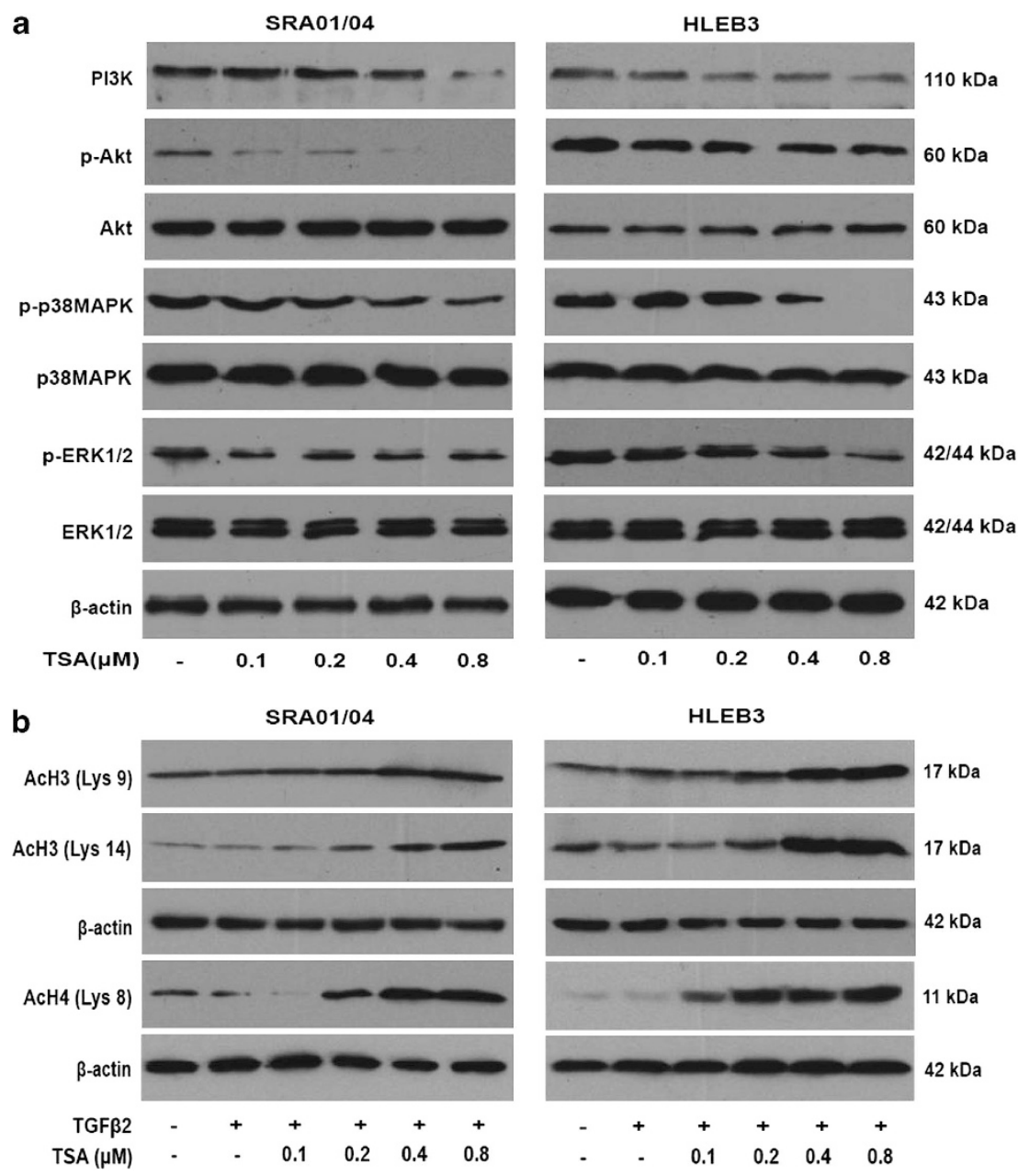

Figure 3 (a) TSA inhibited LECs proliferation through suppressing the PI3K/Akt, p38MAPK and ERK1/2 signaling pathways. SRA01/04 and HLEB3 cell lines were treated with TSA at various concentrations $(0.1,0.2,0.4$ and $0.8 \mu \mathrm{M})$ for $60 \mathrm{~min}$, then the protein expression levels of PI3K, p-Akt, Akt, p-p38MAPK, p38MAPK, p-ERK1/2 and ERK1/2 were detected by western blot analysis. (b) TSA increased the levels of acetylated histones $\mathrm{H} 3$ and H4. The expression of acetylated histones H3 (Lys 9 and 14) and H4 (Lys8) were detected after $12 \mathrm{~h}$ treatment. $\beta$-Actin, loading control. All experiments were repeated three times with similar results

cell lines (Figures 7a and b: ${ }^{*} P<0.05$ versus TGF $\beta 2$ treated with DMSO group; Figure 7c). Altogether, these results suggest that TSA abrogates TGF $\beta 2$-induced EMT through downregulating the Jagged/Notch pathway.

TSA abrogated TGF $\beta 2$-induced ASC in the whole lens culture semi-in vivo model. Previous studies have identified that TGF $\beta$ can induce the whole lens cultured in vitro to form opacities that contain morphologic and biochemical markers for ASC. ${ }^{28}$ To further investigate whether TSA can reverse TGF $\beta 2$-induced $\mathrm{EMT}$ in eye lens in a more complicated system, we used the whole lens culture semiin vivo model. When the lenses from 21 to 22 days rats were cultured with $5 \mathrm{ng} / \mathrm{ml}$ of TGF $\beta 2$ for 7 days, lenses developed obvious clumpy anterior opacities just beneath the lens capsule in each lens, whereas TSA abrogated TGF $\beta 2$ induced ASC and the lenses remained transparent as cultured without TGF $\beta 2$ (Figure 8a). As shown in Figure $8 \mathrm{~b}$, the morphology of the frozen sections showed that the aberrant cells were colocalized with the subcapsular clumpy opacities. The clumps contained accumulations of
FN and Col IV as shown by staining of the sections. The expression of $\alpha$-SMA and vimentin were increased in the clumps. In contrast, the lenses cultured with TSA remained transparent, retained normal lens morphology, and did not have accumulation of FN, Col IV, $\alpha$-SMA and vimentin, but instead, just as lenses cultured without TGF $\beta 2$ (Figures $8 \mathrm{a}$ and b). In addition, we also demonstrated that TSA dramatically reduced the upregulation of mRNA expression of $\alpha$-SMA, Col I, FN, Snail and Slug in rat lenses induced by TGF $\beta 2$ for 7 days (Figure $8 \mathrm{c}$ : ${ }^{\star} P<0.05$ versus TGF $\beta 2$ treated with DMSO group). Taken together, these data indicate that inhibition of HDACs activity can completely abrogated TGF $\beta 2$-induced ASC in rat lens.

\section{Discussion}

In this study, we evaluated the expression profile of HDAC family in TGF $\beta 2$-induced EMT for the first time, and reported that several family members of class I and II HDACs were upregulated in TGF $\beta 2$-induced EMT in human LECs. Inhibition of HDAC activity with TSA, a class I and II HDAC inhibitor, 

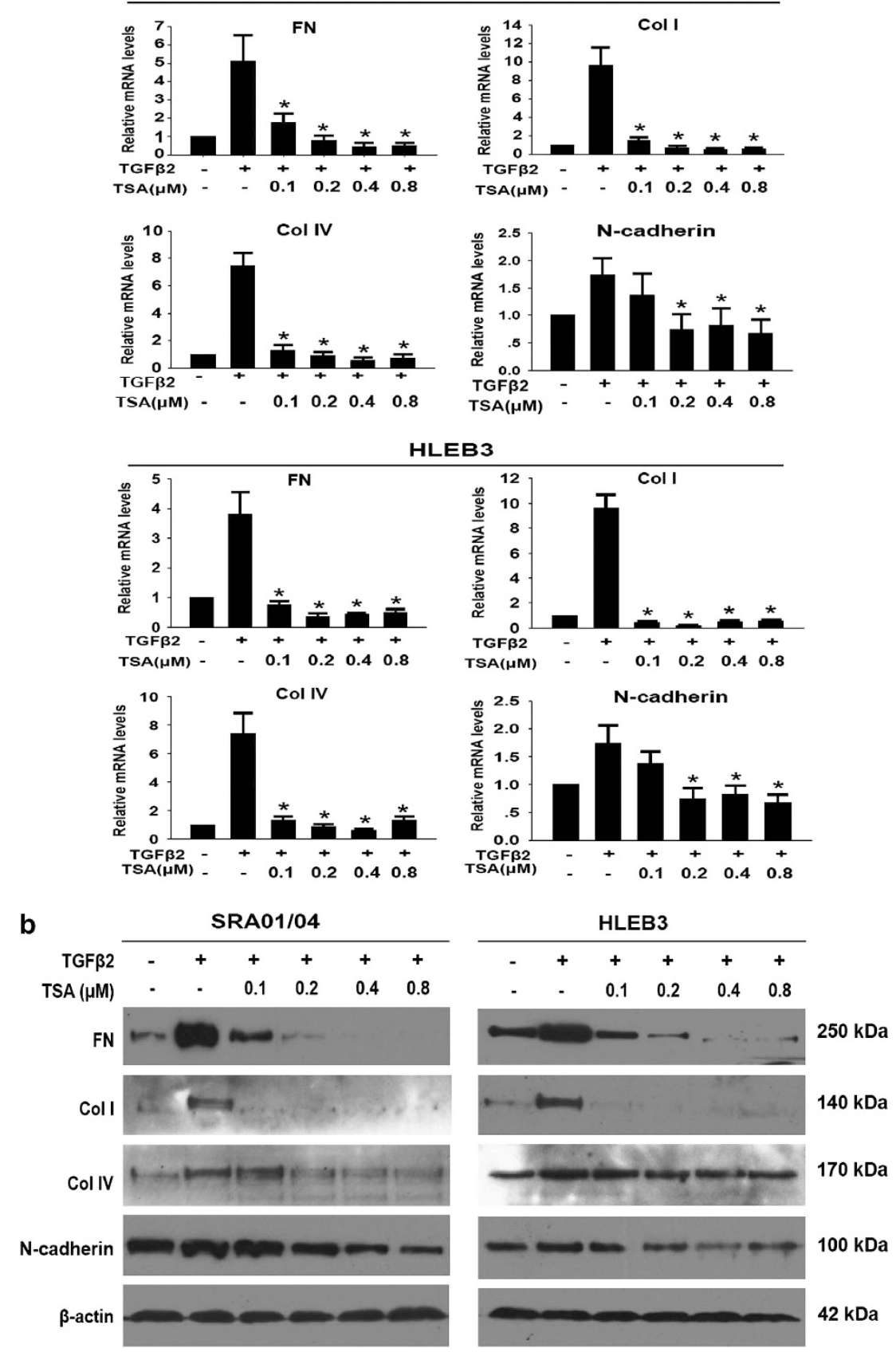

Figure 4 TSA prevents TGF $\beta 2$-induced EMT in LECs. Cells were cultured in the absence or presence of TGF $\beta 2$ with TSA or DMSO for $24 \mathrm{~h}$. (a) The mRNA expression levels of FN, Col I, Col IV and N-cadherin in SRA01/04 and HLEB3 cell lines were determined by real-time quantitative PCR. Gene expression levels were normalized to the glyceraldehyde 3-phosphate dehydrogenase control. ${ }^{*} P<0.05$ versus TGF $\beta 2$ treated with DMSO group. (b) The protein expression levels of FN, Col I, Col IV and N-cadherin in SRA01/04 and HLEB3 cell lines were detected by western blot analysis. $\beta$-Actin, loading control. All experiments were repeated three times with similar results

dramatically suppressed the proliferation of LECs by cell cycle arrest and inhibition of the PI3K/Akt, p38MAPK and ERK1/2 pathways. Moreover, TSA strongly prevented TGF $\beta 2$-induced EMT in LECs through blocking the canonical TGF $\beta /$ Smad2 signal transduction and downregulating the Jagged/Notch signaling pathway. We also demonstrated that TSA completely prevented TGF $\beta 2$-induced ASC in the whole lens culture semi-in vivo model. Therefore, our study provides convincing evidence that epigenetic regulators, HDAC inhibitors, may be a novel strategy for the prevention and treatment of ASC and PCO.

The mammalian cell cycle is controlled by complexes containing cyclins and CDKs and their related pathways. ${ }^{29}$ Cyclins bind and activate their selected CDKs in specific phases of cell cycle, following which they phosphorylate their target proteins to promote cell cycle progression. For example, cyclin D1 and cyclin E1 bind and activate CDK4/6 and CDK2, respectively, and promote the G1 to 
a

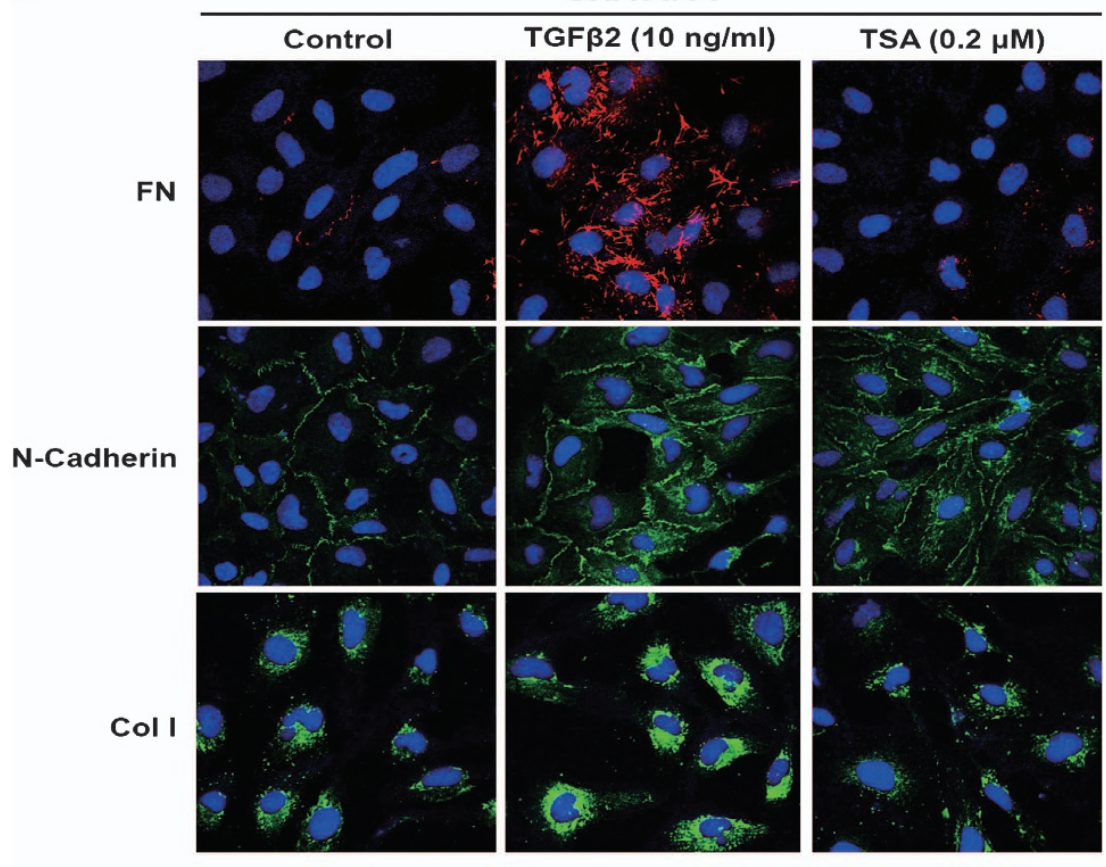

b

HLEB3

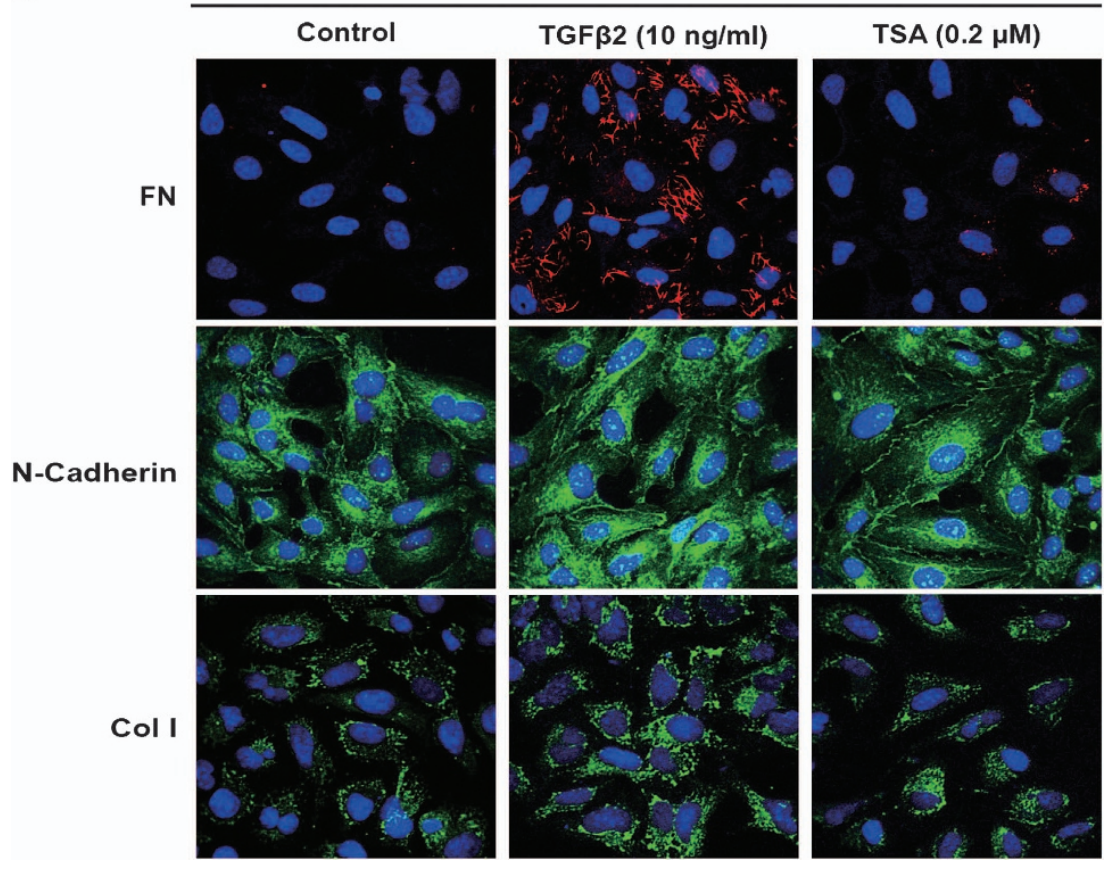

Figure 5 TSA prevents TGF $\beta 2$-induced EMT in LECs. Cells were cultured in the absence or presence of TGF $\beta 2$ with TSA $(0.2 \mu \mathrm{M})$ or DMSO for $24 \mathrm{~h}$. Immunofluorescence analysis of FN (red), N-cadherin (green) and Col I (green) in SRA01/04 (a) and HLEB3 (b) cell lines were observed using confocal microscopy. Representative images are shown (magnification, $\times 400$ ). All experiments were repeated three times with similar results

S phase transition. ${ }^{30}$ Nevertheless, CDK inhibitors, such as P21 and P27, negatively regulate cell cycle progression by inhibiting the activity of the cyclin D1/CDK4/6 and cyclin E/ CDK2 complexes. ${ }^{30}$ Therefore, targeting cyclin/CDK complexes is considered a promising strategy for a number of cancers treatment. In this study, TSA treatment has a significant, dose-dependent inhibitory effect on cyclin
D1/CDK4/6 and cyclinE1/CDK2 complexes, and a stimulative effect on P21 and P27 expression in both SRA01/04 and HLEB3 cell lines. These results provide convincing evidence that TSA exerts its inhibitory effects on cell cycle progression primarily via inhibiting cyclin D1/CDK4/6 and cyclin E1/CDK2 complexes, and inducing P21 and P27. Furthermore, G1 cell cycle arrest is a potential mechanism of growth inhibition effect of TSA in LECs. 

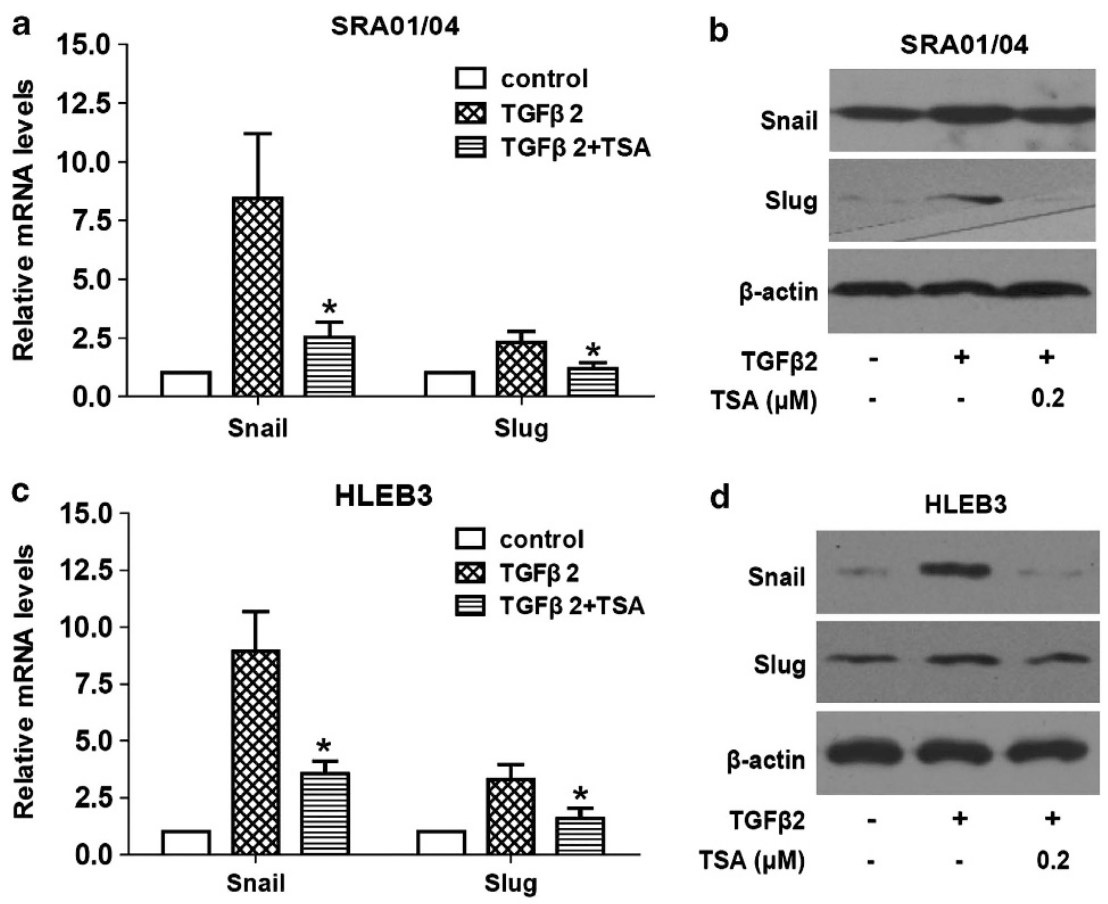

d
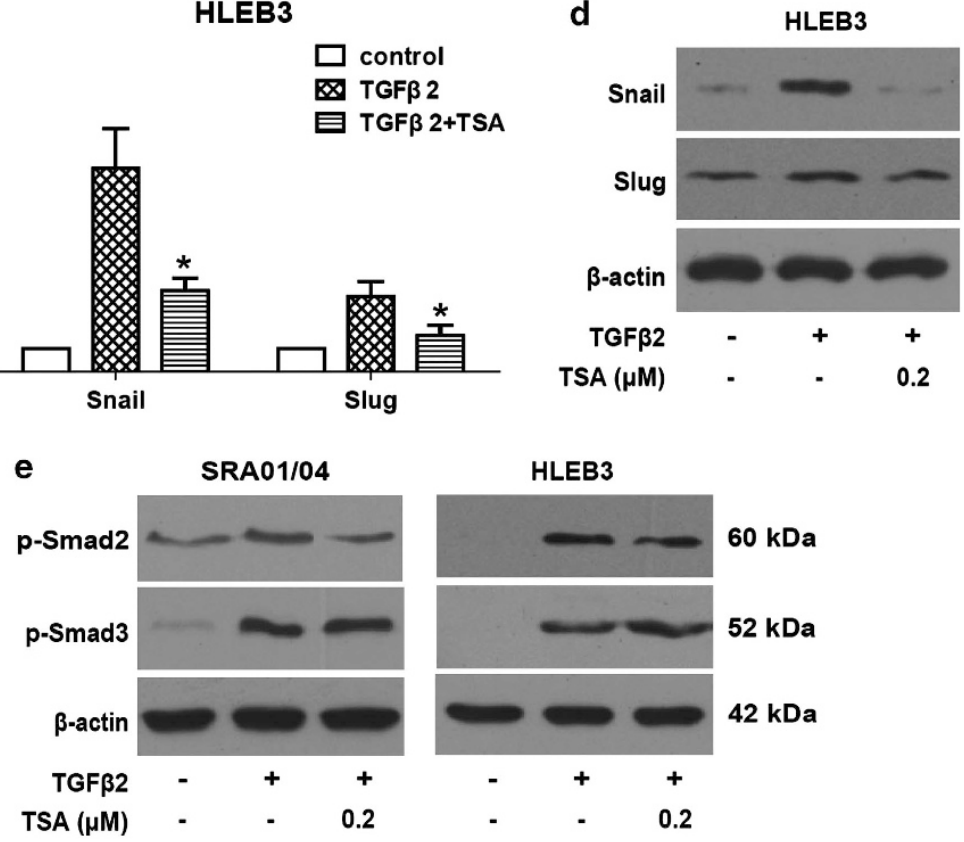

Figure 6 TSA abrogates TGF $\beta 2$-induced upregulation of Snail and Slug, and phosphorylation of Smad2. Cells were cultured in the absence or presence of TGF $\beta 2$ with TSA $(0.2 \mu \mathrm{M})$ or DMSO for $24 \mathrm{~h}$, the mRNA and protein expression of Snail and Slug in SRA01/04 were detected by real-time PCR (a) and western blot analysis (b), respectively. (c) The mRNA expression of Snail and Slug in HLEB3 were detected by real-time PCR. (d) The protein expression of Snail and Slug in HLEB3 were detected by western blot analysis. Gene expression levels were normalized to the glyceraldehyde 3-phosphate dehydrogenase control. ${ }^{*} P<0.05$ versus TGF $\beta 2$ treated with DMSO group. (e) The phosphorylation levels of Smad2 and Smad3 were detected by western blot analysis after 60 min treatment. $\beta$-Actin, loading control. All experiments were repeated three times with similar results

As is well known, the PI3K/Akt and MAPK signaling pathways are important signal transducers for cell proliferation, differentiation and survival, and also serve as key factors in the regulation of cancer cell invasion and metastasis. ${ }^{24,25}$ Therefore, recent studies have focused on inhibiting the PI3K/Akt and MAPKs pathways as potential targets for treating cancers. In addition, the PI3K/Akt and MAPKs pathways are also involved in the proliferation and migration of LECs. ${ }^{31,32}$ In our study, TSA inhibited the expression of PI3K, as well as reduced the phosphorylation of Akt, p38MAPK and ERK1/2 in a dosedependent manner in both SRA01/04 and HLEB3 cell lines. These results indicate that TSA potently inhibits the activation of the PI3K/Akt, p38MAPK and ERK1/2 pathways, leading to a significant decrease in cell growth. This may be another potential mechanism of growth inhibition effect of TSA in LECs.

Emerging evidence is increasingly showing that aberrant expression of HDACs may contribute to the development and progression of various cancers and many other diseases. ${ }^{33,34}$
Recent clinical trials about HDAC inhibitors have shown encouraging results in different cancers. ${ }^{16}$ In present study, we identified that HDAC1, HDAC2, HDAC3, HDAC5, HDAC8 and HDAC10 were upregulated in TGF $\beta 2$-induced EMT in SRA01/04 cells, meanwhile, HDAC2, HDAC5 and HDAC10 were upregulated in TGF $\beta 2$-induced HLEB3 cells. Earlier studies have reported that HDAC1 is required for TGF $\beta$ induced EMT and cell migration in hepatocytes, and HDAC inhibitors completely suppress TGF $\beta$-induced EMT in murine hepatocytes. ${ }^{20}$ HDAC2 is also upregulated in TGF $\beta$-induced EMT in rat kidney tubular epithelial cells and streptozotocininduced diabetic nephropathy. ${ }^{20,35} \mathrm{Wu}$ et al. also revealed that HDAC3 is essential for hypoxia-induced EMT in liver cells. ${ }^{36}$ Taken together, our results coincide with these previous findings, however, there is no existing report concerning the role of HDAC5, HDAC8 and HDAC10 in EMT. So it will be interesting and valuable to determine their possible roles in EMT in future studies. 
a

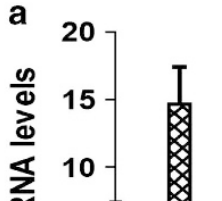

SRA01/04
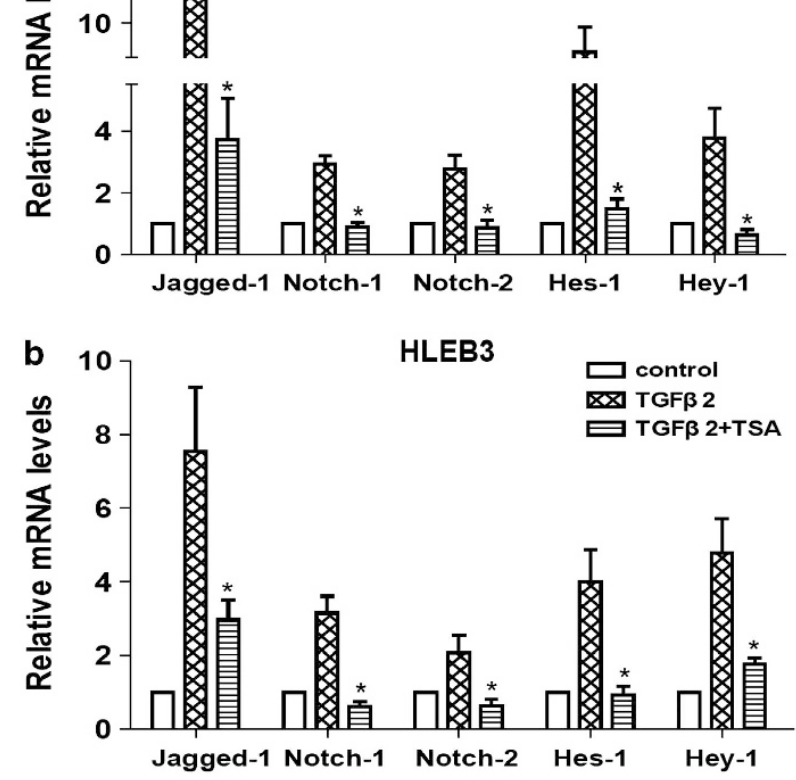

c

SRA01/04
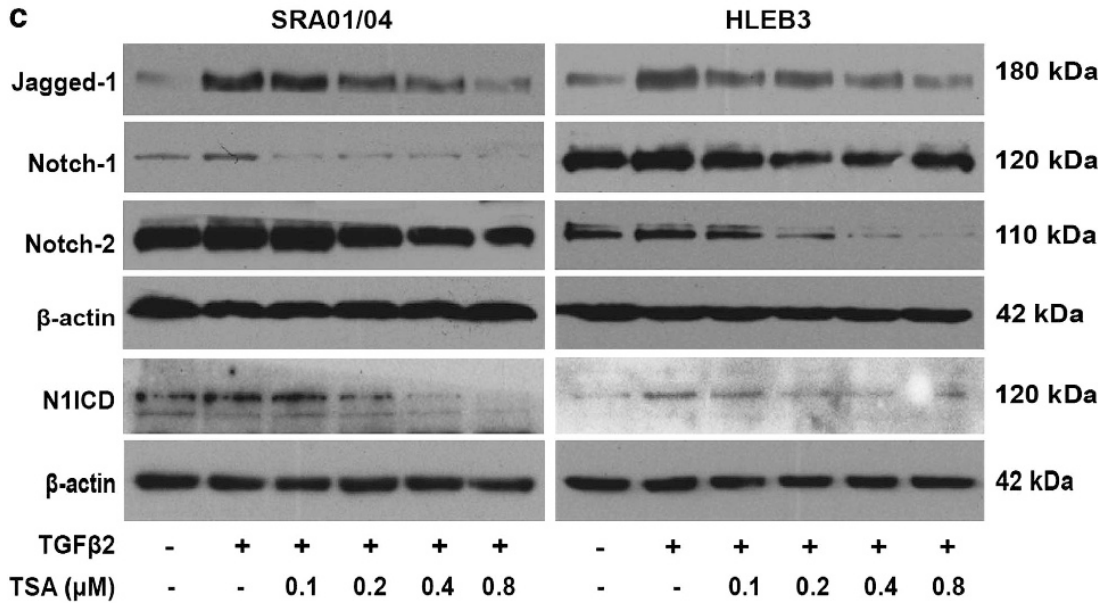

Figure 7 TSA abrogates TGF $\beta 2$-induced EMT via downregulating the Notch pathway. (a) The mRNA expression levels of Jagged-1, Notch-1, Notch-2, Hes-1 and Hey-1 were detected by real-time PCR in SRA01/04 cell line treated with TGF $\beta 2$ in the presence of TSA $(0.2 \mu \mathrm{M})$ or DMSO for $24 \mathrm{~h}$. (b) The mRNA expression levels of Jagged-1, Notch-1, Notch-2, Hes-1 and Hey-1 in HLEB3 cell line were also detected by real-time PCR. Gene levels were normalized to control glyceraldehyde 3-phosphate dehydrogenase. ${ }^{*} P<0.05$ versus TGF $\beta 2$ treated with DMSO group. (c) Representative Jagged-1, Notch-1, Notch-2 and N1ICD immunoblot from SRA01/04 and HLEB3 cell lines treated with TGF $\beta 2$ in the presence of TSA $(0.1,0.20 .4$ and $0.8 \mu \mathrm{M})$ or DMSO for $24 \mathrm{~h}$. All experiments were repeated three times with similar results

To testify our hypothesis that inhibition of HDACs can abrogate TGF $\beta$-induced EMT in LECs, we used TSA, a class I and II HDAC inhibitor. As expected, the results showed that inhibition of HDACs is capable of reducing the expression of mesenchymal markers (i.e., FN, Col I, Col IV and N-cadherin) and transcription factors (Snail and Slug) completely in both SRA01/04 and HLEB3 cell lines. Next, we wished to determine the underlying molecular mechanism of EMT prevention effect of TSA in LECs.

TGF $\beta$ signaling has been established as a central mediator in numerous fibrotic diseases. Specific targeting of the TGF $\beta$ signaling pathway is a critical and effective therapeutic strategy for fibrosis. The canonical TGF $\beta$ signaling transmits its signals through binding to two transmembrane type I and type II receptors, which subsequently recruits and activates receptorregulated Smad proteins-Smad2 and/or Smad3. ${ }^{37}$ The phosphorylation of Smad2 and Smad3, leads them to be dissociated from TGF $\beta$ receptor I and form complexes with Smad4, then translocate to the nuclear and regulate target genes expression. ${ }^{38}$ Therefore, the inhibition of phosphorylation of Smad2 and Smad 3 is able to arrest TGF $\beta$ signaling pathway transduction. In our study, we demonstrated that TSA inhibited TGF $\beta 2$ induced-phosphorylation of Smad2, but has no effect on Smad3 in both SRA01/04 and HLEB3 cell lines. Hence, this indicates that TSA abrogates TGF $\beta 2$-induced EMT via partly affecting the canonical TGF $\beta /$ Smad2 signaling. 
a

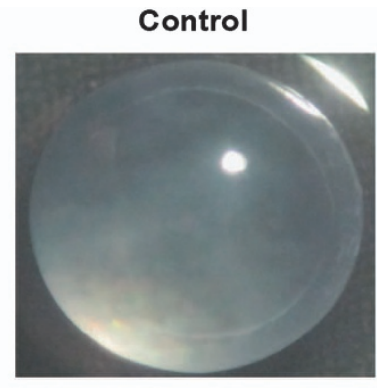

b

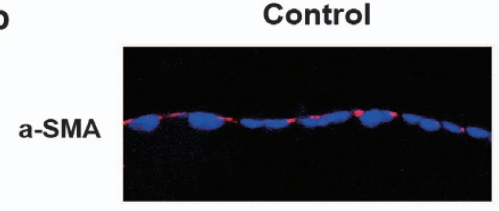

Col IV

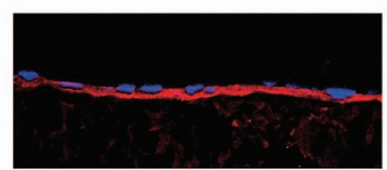

FN
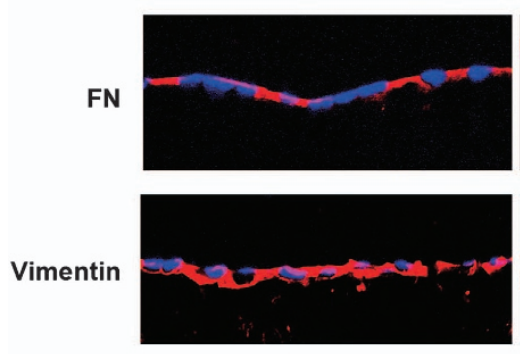

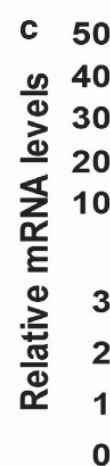

TGFß2 $(5.0 \mathrm{ng} / \mathrm{ml})$

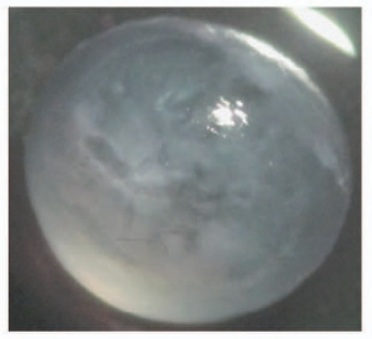

TGF $\beta 2(5.0 \mathrm{ng} / \mathrm{ml})$
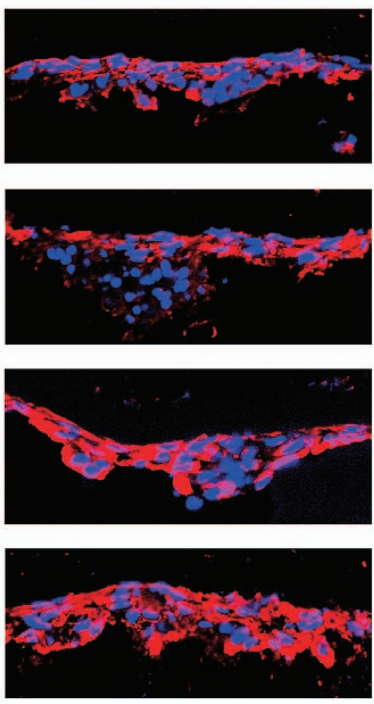

TSA $(0.4 \mu \mathrm{M})$

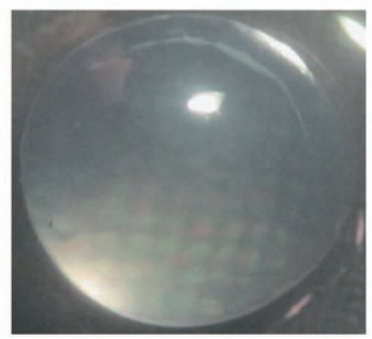

TSA $(0.4 \mu \mathrm{M})$
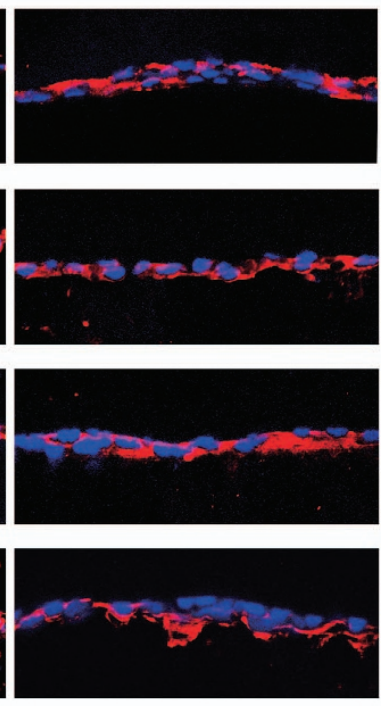

control

$\otimes$ TGF 2

TGF $\beta$ 2+TSA

Figure 8 TSA abrogated TGF $\beta 2$-induced ASC in the whole lens culture semi-in vivo model. Lenses were cultured in the absence or presence of TGF $\beta 2$ with TSA (0.4 $\mu$ M) or DMSO for 7 days. (a) The morphology of the lenses was photographed using a dissecting microscope. $n=12$. (b) The staining of frozen sections for $\alpha$-SMA (red), Col IV (red), FN (red) and vimentin (red). Images were captured using a fluorescence confocal microscope. $n=6$. Bar, $20 \mu \mathrm{m}$. (c) The mRNA expression levels of $\alpha-S M A$, Col I, FN, Snail and Slug in lenses were detected by real-time PCR. $n=6$. Gene levels were normalized to control glyceraldehyde 3-phosphate dehydrogenase. ${ }^{*} P<0.05$ versus TGF $\beta 2$ treated with DMSO group

Recently, an increasing number of studies show that the Notch signaling pathway is a key regulator in inducing EMT during embryonic development, fibrotic diseases and cancer metastasis. $^{27}$ Elevated Jagged/Notch signaling has been verified in a large range of fibrotic diseases in the kidney, liver and lung. ${ }^{39}$ Moreover, our previous study also demonstrated that the Notch signaling is required in TGF $\beta 2$-induced EMT in LECs and retinal pigment epithelium cells (data unpublished). In TGF $\beta 2$-induced EMT in LECs, the elements of the Notch signaling pathway, including Jagged-1, Notch-1, Notch-2, together with their target genes Hes-1 and Hey-1, were upregulated, whereas blockade of Notch pathway inhibited TGF $\beta 2$-induced EMT (data unpublished). In this study, we found that TSA can markedly attenuate TGF $\beta 2$-induced upregulation of Jagged-1, Notch-1, Notch-2, N1ICD, Hes-1 and Hey-1. Collectively, these results provide convincing evidence that the inactivation of Jagged/Notch signaling by TSA is another potential mechanism of EMT abrogation in LECs. 
Finally, to further investigate whether TSA can prevent TGF $\beta 2$-induced EMT in eye lens in a more complicated system, we used the whole lens culture semi-in vivo model. The ocular lens is an excellent model to study cell behavior. ${ }^{3}$ The lens is made up of an anterior monolayer of LECs that overlie a mass of aligned fiber cells, all surrounded by the lens capsule. Numerous studies have shown that abnormal TGF $\beta$ signaling in the eye results in EMT of LECs that bear a morphologic and molecular resemblance to some forms of human cataract, including ASC and PCO. ${ }^{6,28,40}$ In present study, using the whole lens culture model, we found that inhibition of HDAC activity with TSA in cultured lenses effectively blocked TGF $\beta 2$ induced EMT and cataract formation in this semi-in vivo model.

In summary, our results provided, for the first time, evidence that several family members of class I and II HDACs were upregulated in TGF $\beta 2$-induced EMT in human LECs. Inhibition of HDAC activity with TSA strongly inhibits the proliferation and TGF $\beta 2$-induced EMT in human LECs. The mechanism underlying proliferation suppression by TSA is the cell cycle arrest and inactivation of the PI3K/Akt, p38MAPK and ERK1/2 pathways. Meanwhile, the underlying mechanism of EMT inhibition by TSA is blockade of the canonical TGF $\beta /$ Smad2 and Jagged/Notch signaling pathways. Therefore, this study provides a new insight into the pathogenesis of ASC and PCO in an epigenetic aspect. Epigenetic regulators, represented by HDAC inhibitors, may be novel therapeutic agents for the prevention and treatment of ocular fibrotic diseases, such as ASC and PCO.

\section{Materials and Methods}

Reagents and antibodies. Recombinant human TGF $\beta 2$ was purchased from Cell Signaling (Danvers, MA, USA). TSA (a class I and II HDAC inhibitor) was purchased from Sigma-Aldrich (Louis, MO, USA). Antibodies against cyclin D1, cyclin E1, CDK2, CDK4, CDK6, P21, P27, acetyl-histone H3 (Lys9), acetylhistone H3 (Lys14), acetyl-histone H4 (Lys8), Jagged-1, Notch-1, Notch-2, p-Smad2/3, Snail, Slug, Pl3K, p-Akt, Akt, p38MAPK, p-p38MAPK, ERK1/2, $p$-ERK $1 / 2$, horse anti-mouse and goat anti-rabbit horseradish peroxidase conjugates secondary antibodies, Alexa Fluor 488-conjugated goat anti-rabbit and Alexa Fluor 555-conjugated donkey anti-mouse secondary antibodies were purchased from Cell Signaling. Antibodies against $\beta$-actin, FN, Col I, Col IV, N-cadherin, $\alpha$-SMA, vimentin and N1ICD were purchased from Abcam (Cambridge, UK). CCK-8 kit was purchased from Dojindo (Shanghai, China).

Cells culture and treatment. The human lens epithelial cell line SRA01/04 and HLEB3 were cultured in Dulbecco's modified Eagle's medium containing 10\% fetal bovine serum. The cells were grown at $37^{\circ} \mathrm{C}$ in a humidified atmosphere containing $5 \% \mathrm{CO}_{2}$ and dissociated with $0.25 \%$ trypsin-0.02\% EDTA solution.

For TGF $\beta 2$ and TSA treatments, the cells were grown in six-well plates and treated with $10 \mathrm{ng} / \mathrm{ml}$ recombinant human TGF $\beta 2$ and various concentrations of TSA for different time points.

Cell proliferation assay. To assess proliferation, LEC lines SRA01/04 and HLEB3 were seeded into 96 -well plates at the density of $5 \times 10^{3}$ cells/well and grown overnight. Then the cells were treated with increasing doses of TSA for 24 and $48 \mathrm{~h}$, respectively. At the end of the treatment period, $10 \mu \mathrm{l}$ of CCK-8 solution was added to each well and incubated for $2 \mathrm{~h}$. The absorbance $(A)$ at $450 \mathrm{~nm}$ was measured using a microplate reader.

Cell apoptosis assay. Cells were seeded on six-well plates and treated with increasing doses of TSA for $48 \mathrm{~h}$, and then cells were harvested, washed with PBS and stained with Annexin V-FITC/PI (Becton Dickinson, Franklin
Lakes, NJ, USA) at room temperature for $15 \mathrm{~min}$. Samples were analyzed by flow cytometry.

Cell-cycle analysis. Cells were treated with increasing doses of TSA for $24 \mathrm{~h}$, and then cells were harvested and fixed in cold $70 \%$ ethanol overnight at $4{ }^{\circ} \mathrm{C}$. The cells were centrifuged down and resuspended in $0.2 \mathrm{ml}$ propidium iodide staining solution for $45 \mathrm{~min}$ incubation at room temperature. Finally, the DNA content of cells was measured using a flow cytometry (BD Biosciences, San Jose, CA, USA).

Scratch wound assay. The effect of TSA on TGF $\beta 2$-induced migration of LECs was evaluated by scratch wound assay. In brief, LECs was wounded using a $100-\mu$ l yellow micropipette tip and incubated with TGF $\beta 2$ in the presence or absence of TSA for $24 \mathrm{~h}$. Wound closure was monitored under an inverted phasecontrast microscope and photographed in digital format $(\times 50)$ after incubation for $24 \mathrm{~h}$. For quantitative assessment, the area of the wound was determined by Image-Pro Plus software 5.1 (Media Cybernetics, Inc. Silver Spring, MD, USA).

Real-time PCR analysis for gene expression. Total RNA was isolated from LECs and rat lenses using Trizol reagent (Invitrogen, Carlsbad, CA, USA). The concentration of total RNA was quantified by spectrophotometry and CDNA was synthesized with a reverse transcription kit (Takara; Siga, Japan). For quantitative analysis of mRNA expression, SYBR PrimeScript RT-PCR kit (Takara) was used to amplify the target genes and reactions were performed with the $A B I$ Prism 7000 sequence detection system (Applied Biosystems, Foster City, CA, USA) according to the manufacture's protocol. Glyceraldehyde 3-phosphate dehydrogenase was used as an internal control.

Immunofluorescence. LECs $\left(1 \times 10^{5}\right)$ were grown on cover slips in six-well plates and treated as described previously. After fixed with acetone for $10 \mathrm{~min}$ and permeabilized with $0.1 \%$ Triton $X-100$ for 5 min, cells were blocked with $1 \%$ bovine serum albumin (BSA) in PBS for $1 \mathrm{~h}$. Then they were incubated with different primary antibodies (diluted in blocking solution) at $4^{\circ} \mathrm{C}$ overnight. On the next day, cells were incubated with Alexa Fluor 555-conjugated donkey anti-mouse or Alexa Fluor 488-conjugated goat anti-rabbit secondary antibody $(1: 200)$ for $1 \mathrm{~h}$ at room temperature. After washing with PBS containing $0.1 \%$ Tween-20, cells were incubated with $50 \mathrm{ng} / \mathrm{ml} \mathrm{DAPI}$ for 5 min to stain nuclei. The slides were mounted with anti-fade fluorescent mounting medium and images were acquired by a fluorescence confocal microscope (LSM510; Carl Zeiss, Oberkochen, Germany).

Western blot analysis for protein expression. Cells were lysed in RIPA buffer and protein was collected after centrifugation and mixed with $5 \times$ SDS sample buffer. The samples were separated by $10 \%$ SDS-PAGE, and then transferred to PVDF membranes. The membranes were blocked in $5 \%$ nonfat milk for $1 \mathrm{~h}$ and subsequently incubated with different primary antibodies at $4{ }^{\circ} \mathrm{C}$ overnight. After $1 \mathrm{~h}$ incubation with horseradish peroxidase-conjugated secondary antibodies, the protein bands were detected with chemiluminescence detection reagents. $\beta$-Actin was used as loading control.

Lens culture and treatment. All experimental procedures conformed to the ARVO Statement for the Use of Animals in Ophthalmic and Vision Research. Lenses of 21-22 days Wistar rats were culture as described previously. ${ }^{28,41}$ Briefly, whole lenses were carefully removed using forceps and a pair of fine scissors, and maintained in $4 \mathrm{ml}$ serum-free M199 medium (two lenses per dish) containing $0.1 \% \mathrm{BSA}, 0.1 \mathrm{mg} / \mathrm{ml}$ L-glutamine, $50 \mathrm{IU} / \mathrm{ml}$ penicillin and $50 \mathrm{mg} / \mathrm{ml}$ streptomycin. TGF $\beta 2$ and TSA were added to the culture medium at the final concentrations of $5 \mathrm{ng} / \mathrm{ml}$ and $0.4 \mu \mathrm{M}$, respectively. Culture medium was renewed every second day throughout the culture period. Lenses were cultured for up to 7 days and photographed using a dissecting microscope.

Immunofluorescent staining of frozen sections. At the end of the culture period, the lenses were embedded in optimal cutting temperature compound at $-20^{\circ} \mathrm{C}$. Sections $(6 \mu \mathrm{m})$ were cut using a cryostat and fixed in cold acetone for $10 \mathrm{~min}$, then permeabilized with $0.1 \%$ Triton X-100 for $5 \mathrm{~min}$. Sections were then blocked with $1 \%$ BSA in PBS for $1 \mathrm{~h}$ followed by overnight incubation with different primary antibodies (dilution in above buffer) at $4{ }^{\circ} \mathrm{C}$ in a humidity chamber. Next day, the sections were incubated with Alexa Fluor 555-conjugated donkey anti-mouse secondary antibody $(1: 200)$ for $1 \mathrm{~h}$ at room temperature. After staining the nuclei, sections were mounted and images were captured using a fluorescence confocal microscope. 
Statistical analysis. Experiments presented in the figures were representative of three or more different repetitions. All data were expressed as mean \pm S.E.M. and analyzed with SPSS 15.0 software (SPSS Inc., Chicago, IL, USA). One-way analysis of variance was used to compare differences among groups. A value of $P<0.05$ was considered statistically significant.

\section{Conflict of Interest}

The authors declare no conflict of interest.

Acknowledgements. The research was funded by the grant from the National Natural Science Foundation of China (no. 81270981 and 81000371).

1. McCarty CA, Taylor HR. Recent developments in vision research: light damage in cataract. Invest Ophthalmol Vis Sci 1996; 37: 1720-1723.

2. Nathu Z, Dwivedi DJ, Reddan JR, Sheardown H, Margetts PJ, West-Mays JA. Temporal changes in MMP mRNA expression in the lens epithelium during anterior subcapsular cataract formation. Exp Eye Res 2009; 88: 323-330.

3. Shin EH, Basson MA, Robinson ML, McAvoy JW, Lovicu FJ. Sprouty is a negative regulator of transforming growth factor beta-induced epithelial-to-mesenchymal transition and cataract. Mol Med 2012; 18: 861-873.

4. Apple DJ, Solomon KD, Tetz MR, Assia El, Holland EY, Legler UF et al. Posterior capsule opacification. Surv Ophthalmol 1992; 37: 73-116.

5. Hodge WG. Posterior capsule opacification after cataract surgery. Ophthalmology 1998; 105: $943-944$

6. Srinivasan Y, Lovicu FJ, Overbeek PA. Lens-specific expression of transforming growth factor beta1 in transgenic mice causes anterior subcapsular cataracts. J Clin Invest 1998; 101: $625-634$

7. de longh RU, Wederell E, Lovicu FJ, McAvoy JW. Transforming growth factorbeta-induced epithelial-mesenchymal transition in the lens: a model for cataract formation. Cells Tissues Organs 2005; 179: 43-55.

8. Wallentin N, Wickstrom K, Lundberg C. Effect of cataract surgery on aqueous TGF-beta and lens epithelial cell proliferation. Invest Ophthalmol Vis Sci 1998; 39: 1410-1418.

9. Meacock WR, Spalton DJ, Stanford MR. Role of cytokines in the pathogenesis of posterior capsule opacification. Br J Ophthalmol 2000; 84: 332-336.

10. Allen JB, Davidson MG, Nasisse MP, Fleisher LN, McGahan MC. The lens influences aqueous humor levels of transforming growth factor-beta 2. Graefes Arch Clin Exp Ophthalmol 1998; 236: 305-311.

11. Awasthi N, Guo S, Wagner BJ. Posterior capsular opacification: a problem reduced but not yet eradicated. Arch Ophthalmol 2009; 127: 555-562.

12. Reichert N, Choukrallah MA, Matthias P. Multiple roles of class I HDACs in proliferation, differentiation, and development. Cell Mol Life Sci 2012; 69: 2173-2187.

13. Tang J, Yan $\mathrm{H}$, Zhuang S. Histone deacetylases as targets for treatment of multiple diseases. Clin Sci (Lond) 2013; 124: 651-662.

14. Duan $H$, Heckman CA, Boxer LM. Histone deacetylase inhibitors down-regulate bcl-2 expression and induce apoptosis in $t(14 ; 18)$ lymphomas. Mol Cell Biol 2005; 25 : $1608-1619$

15. Henderson C, Mizzau M, Paroni G, Maestro R, Schneider C, Brancolini C. Role of caspases, Bid, and p53 in the apoptotic response triggered by histone deacetylase inhibitors trichostatin-A (TSA) and suberoylanilide hydroxamic acid (SAHA). J Biol Chem 2003; 278: 12579-12589.

16. Barneda-Zahonero B, Parra M. Histone deacetylases and cancer. Mol Oncol 2012; 6 : 579-589.

17. Rombouts K, Niki T, Greenwel $P$, Vandermonde A, Wielant A, Hellemans $K$ et al. Trichostatin $A$, a histone deacetylase inhibitor, suppresses collagen synthesis and prevents TGF-beta(1)-induced fibrogenesis in skin fibroblasts. Exp Cell Res 2002; 278: 184-197.

18. Van Beneden K, Geers C, Pauwels M, Mannaerts I, Wissing KM, Van den Branden C et al. Comparison of trichostatin $\mathrm{A}$ and valproic acid treatment regimens in a mouse model of kidney fibrosis. Toxicol Appl Pharmacol 2013; 271: 276-284.

19. Niki T, Rombouts K, De Bleser P, De Smet K, Rogiers V, Schuppan D et al. A histone deacetylase inhibitor, trichostatin $A$, suppresses myofibroblastic differentiation of rat hepatic stellate cells in primary culture. Hepatology 1999; 29: 858-867.
20. Lei W, Zhang K, Pan X, Hu Y, Wang D, Yuan X et al. Histone deacetylase 1 is required for transforming growth factor-beta1-induced epithelial-mesenchymal transition. Int J Biochem Cell Biol 2010; 42: 1489-1497.

21. Yoshikawa M, Hishikawa K, Marumo T, Fujita T. Inhibition of histone deacetylase activity suppresses epithelial-to-mesenchymal transition induced by TGF-beta1 in human renal epithelial cells. J Am Soc Nephrol 2007; 18: 58-65.

22. Rishikof DC, Ricupero DA, Liu H, Goldstein RH. Phenylbutyrate decreases type I collagen production in human lung fibroblasts. J Cell Biochem 2004; 91: 740-748.

23. Kerl K, Ries D, Unland R, Borchert C, Moreno $\mathrm{N}$, Hasselblatt $\mathrm{M}$ et al. The histone deacetylase inhibitor SAHA acts in synergism with fenretinide and doxorubicin to control growth of rhabdoid tumor cells. BMC Cancer 2013; 13: 286.

24. Willems L, Tamburini J, Chapuis N, Lacombe C, Mayeux P, Bouscary D. PI3K and mTOR signaling pathways in cancer: new data on targeted therapies. Curr Oncol Rep 2012; 14: 129-138.

25. Kim EK, Choi EJ. Pathological roles of MAPK signaling pathways in human diseases Biochim Biophys Acta 2010; 1802: 396-405.

26. Zeisberg M, Neilson EG. Biomarkers for epithelial-mesenchymal transitions. J Clin Invest 2009; 119: 1429-1437.

27. Wang Z, Li Y, Kong D, Sarkar FH. The role of Notch signaling pathway in epithelialmesenchymal transition (EMT) during development and tumor aggressiveness. Curr Drug Targets 2010; 11: 745-751.

28. Hales AM, Chamberlain CG, McAvoy JW. Cataract induction in lenses cultured with transforming growth factor-beta. Invest Ophthalmol Visual Sci 1995; 36: 1709-1713.

29. Hallstrom TC, Nevins JR. Balancing the decision of cell proliferation and cell fate. Cell Cycle 2009; 8: 532-535.

30. Gulappa T, Reddy RS, Suman S, Nyakeriga AM, Damodaran C. Molecular interplay between cdk4 and p21 dictates G0/G1 cell cycle arrest in prostate cancer cells. Cancer Lett 2013; 337: 177-183.

31. Choi J, Park SY, Joo CK. Hepatocyte growth factor induces proliferation of lens epithelial cells through activation of ERK1/2 and JNK/SAPK. Invest Ophthalmol Visual Sci 2004; 45: 2696-2704.

32. Jiang $Q$, Zhou $C$, Bi Z, Wan Y. EGF-induced cell migration is mediated by ERK and PI3K/AKT pathways in cultured human lens epithelial cells. J Ocul Pharmacol Ther 2006; 22: 93-102.

33. Gloghini A, Buglio D, Khaskhely NM, Georgakis G, Orlowski RZ, Neelapu SS et al. Expression of histone deacetylases in lymphoma: implication for the development of selective inhibitors. Br J Haematol 2009; 147: 515-525.

34. Al-Janadi A, Chandana SR, Conley BA. Histone deacetylation: an attractive target for cancer therapy? Drugs R\&D 2008; 9: 369-383.

35. Noh H, Oh EY, Seo JY, Yu MR, Kim YO, Ha H et al. Histone deacetylase-2 is a key regulator of diabetes- and transforming growth factor-beta1-induced renal injury. Am J Physiol Renal Physiol 2009; 297: F729-F739.

36. Wu MZ, Tsai YP, Yang MH, Huang CH, Chang SY, Chang CC et al. Interplay between HDAC3 and WDR5 is essential for hypoxia-induced epithelial-mesenchymal transition. Mol Cell 2011; 43: 811-822.

37. Akhurst RJ, Hata A. Targeting the TGFbeta signalling pathway in disease. Nat Rev Drug Discov 2012; 11: 790-811.

38. Choi ME, Ding Y, Kim SI. TGF-beta signaling via TAK1 pathway: role in kidney fibrosis. Sem Nephrol 2012; 32: 244-252.

39. Leask A. Targeting the jagged/notch pathway: a new treatment for fibrosis? J Cell Commun Signaling 2010; 4: 197-198.

40. Connor TB Jr, Roberts AB, Sporn MB, Danielpour D, Dart LL, Michels RG et al. Correlation of fibrosis and transforming growth factor-beta type 2 levels in the eye. J Clin Invest 1989; 83: $1661-1666$

41. Hales AM, Chamberlain CG, McAvoy JW. Susceptibility to TGFbeta2-induced cataract increases with aging in the rat. Invest Ophthalmol Vis Sci 2000; 41: 3544-3551.

(i) (2) $\odot$ Cell Death and Disease is an open-access journal published by Nature Publishing Group. This work is licensed under a Creative Commons Attribution-NonCommercialNoDerivs 3.0 Unported License. To view a copy of this license, visit http://creativecommons.org/licenses/by-nc-nd/3.0/ 